\title{
Termal Görüntü İşleme İle Diz Osteoartritinin Tespit Edilmesi
}

\author{
Afrah Abdulsattar Jasim Qali ${ }^{1 *}$, Murat Selek ${ }^{2}$, Sameer Saeed Abbas ${ }^{3}$ \\ ${ }^{1}$ Konya Teknik Üniversitesi, Mühendislik Fakültesi, Elektrik-Elektronik Mühendisliği Bölümü, Konya, Türkiye, (ORCID: 0000-0003-1126-9999), \\ afrah.power@gmail.com \\ ${ }^{2}$ Konya Teknik Üniversitesi, Teknik Bilimler Meslek Yüksekokulu, Elektronik ve Otomasyon Bölümü, Konya, Türkiye, (ORCID: 0000-0001-8642-1823), \\ mselek@ktun.edu.com \\ ${ }^{3}$ Ankara Yıldırım Beyazıt Üniversitesi, Mühendislik Fakültesi, Bilgisayar Mühendisliği Bölümü, Ankara, Türkiye, (ORCID: 0000-0001-9600-9883), \\ Samir88eng@gmail.com.
}

(2nd International Conference on Computer, Electrical and Electronic Sciences ICCEES 2021, September 1-3, 2021)

(DOI: 10.31590/ejosat.1028191)

ATIF/REFERENCE: Qali, A., Selek, M. \& Abbas, S. (2021). Termal Görüntü İşleme İle Diz Osteoartritinin Tespit Edilmesi. Avrupa Bilim ve Teknoloji Dergisi, (30), 69-72.

$\ddot{O} \mathbf{z}$

Infrared termografi (IRT), normal ve anormal duyu ve sinir sistemleri, iltihaplanma ya da travma hakkında yerel ve küresel olarak bilgi sağlayan bir tanı aracıdır. Diz osteoartriti (OA), dejeneratif eklem hastalığı olarak da bilinmesine ek olarak tipik bir aşınma, yıpranma ve ilerleyici eklem kıkırdağı kaybının sonucu olmaktadır. Bu çalışmada, OA hastalığının sıcaklık özelliğinden faydalanarak termal kamera ile elde edilen görüntüleri görüntü işleme modelleri (Evrişimsel sinir ağları, Destek Vektör Makineleri ve VGG-16 mimarisi)'inden yararlanarak hastalığın erken teşhisinin yapılması planlanmaktadır. Termografi ile elde edilen görüntülere, söz konusu yöntemler uygulanarak hastalığı en yüksek doğrulukta tahmin edebilen yöntemi bulmak amaçlanmaktadır. Ayrıca en yüksek doğruluk oranını veren yöntem ile arayüz grafiği tasarlayarak hastalığı erken teşhis sürecinde doktora yardımcı olabilmeyi amaçlamaktadır. Toplam 998 görüntü termal kamera ile farklı kişilerden elde edilmiş̧tir. Bu görüntülerin 284’ü hasta, 714'ü ise kontrol grubuna ait görüntülerdir. Termal kamera ile alınan görüntülerdeki renk farklılığı, Osteoartrit hastalığının bulunup bulunmadığını tek başına tespit edemezken yukarıda anılan yöntemler yardımıyla bu hastalığı tespit etme imkânı sağlamaktadır. Uygulanmış olan yöntemler arasında en iyi sınıflandırma sonucu $\% 90$ doğruluk oranı ile evrişimsel sinir ağları yöntemi ile elde edilmiştir. Elde edilen sonuçlar derin öğrenme yöntemlerinin termal görüntülerin sınıflandırılmasında oldukça başarılı olduğunu göstermektedir. Alınan görüntüler SPSS version 25 istatistik paket programında işlenmiş olup tüm istatistiksel analizlerde $\mathrm{p}<0.05$ düzeyinde anlamlı olarak değerlendirilmiştir.

Anahtar Kelimeler: Termografi, Evrişimsel Sinir Ağları, Destek Vektör Makineleri, VGG-16, Osteoartriti.

\section{Detection of Knee Osteoarthritis with Thermal Image Processing}

\begin{abstract}
Infrared thermography (IRT) is a diagnostic tool that provides local and global information about normal and abnormal sensory and nervous systems, inflammation or trauma. In addition to being known as a degenerative joint disease, knee osteoarthritis $(\mathrm{OA})$ is the result of typical wear and tear and progressive loss of articular cartilage. In this study, it is planned to make the early diagnosis of the disease by making use of the image processing models (Convolutional neural networks, Support Vector Machines and VGG-16 architecture) of the images obtained with the thermal camera by taking advantage of the temperature feature of the OA disease. It is aimed to find the method that can predict the disease with the highest accuracy by applying these methods to the images obtained by thermography. In addition, it aims to help the doctor in the early diagnosis of the disease by designing an interface graphic with the method that gives the highest accuracy rate. A total of 998 images were obtained from different people with a thermal camera. Of these images, 284 are images of the patient and 714 of them are images of the control group. While the color difference in the images taken with the thermal camera cannot detect whether there is Osteoarthritis disease on its own, it provides the opportunity to detect this disease with the help of the above-mentioned methods. Among the applied methods, the best classification result was obtained with the convolutional neural network method with $90 \%$ accuracy. The results show that deep learning methods are quite successful in classifying thermal images. The images taken were processed in the SPSS version 25 statistical package program and were evaluated as significant at the $\mathrm{p}<0.05$ level in all statistical analyses.
\end{abstract}

Keywords: Thermography, Convolutional Neural Networks, Support Vector Machines, VGG-16, Osteoarthritis.

\footnotetext{
* Sorumlu Yazar: Konya Teknik Üniversitesi, Mühendislik Fakültesi, Elektrik-Elektronik Mühendisliği Bölümü, Konya, Türkiye, (ORCID: 00000003-1126-9999), afrah.power@gmail.com
} 


\section{Giriş}

Kızılötesi radyasyon, elektromanyetik spektrumun görünür ve mikrodalga bölümleri arasında bulunmaktadır. Kızılötesi radyasyonun ilk kaynağı termal ya da isı radyasyondur. Mutlak sıfirın (-273.15 santigrat derece veya 0 Kelvin) üzerinde bir 1sıya sahip herhangi bir nesne, kızılötesi alanda radyasyon yaymaktadır. Her gün kızılötesi radyasyona maruz kalmaktayız. Güneş 1şığı, ateş ya da radyatörden hissettiğimiz 1sı tamamen kızılötesidir. Gözle görülmese bile ciltteki sinirler 1S1 olarak hissedilebilmektedir. Nesne ne kadar sıcak olursa, o kadar çok kızı̈ötesi radyasyon yayar (Anonymous, 2021).

Osteoartrit en çok yaygın kas-iskelet sistemi hastalığ olup yaşlı erişkinlerde önemli bir sakatlık nedeni olmaktadır (Lawrence ve ark., 2008). Yaşlı nüfus üzerindeki OA etkisi gittikçe daha belirgin duruma geldiğinden oldukça büyük bir klinik yük durumuna gelmiştir (Felson ve ark., 1995). OA omurga, el ve kalça dâhil olmak üzere çeşitli eklemleri etkilese dahi, klinik öneme sahip olduğu için OA araştırmalarının ve görüntülemelerinin büyük bir kısmı diz eklemi üzerinde yoğunlaştığından dolayı bu çalışma diz eklemi konusunda OA'ya odaklanmaktadır (Bijlsma ve ark., 2011).

Evrişimsel Sinir Ağları (ESA), birden fazla tabakanın iyi bir şekilde eğitildiği çok önemli derin öğrenme yaklaşımlarından biri olmaktadır ( Lecun ve ark., 1998). Söz konusu yöntem çok etkili bulunmakta ve aynı zamanda çeşitli bilgisayar uygulamalarında oldukça yaygın bir şekilde kullanılmaktadır (Krizhevsky ve ark., 2012).

Hem sınıflandırma hem de regresyon için kullanılmakta olan Destek vektör makineleri (SVM), güçlü fakat esnek denetime sahip makine öğrenme algoritmaları olmaktadır. Fakat genel olarak sınıflandırma sorunlarında kullanılmaktadır. SVM'ler 1960'larda ilk kez tanıtılmış ve daha sonra 1990'da rafine edilmiştir. SVM'ler, diğer makine öğrenme algoritmaları ile kıyaslandığında benzersiz uygulama metotlarına sahiptir. Son çalışmalarda, birden fazla devamlı ve kategorik değişkeni ele alma kabiliyetlerinden dolayı oldukça popüler olmuştur (Anonymous, 2021).

VGG-16 eğitilmiş ağ olup sınıflandırmadaki performansı ve asgari hata verdiği için bu derlemede kullanılmıştır (Erdem ve Aydın, 2021). Termal görüntüler üzerinde makine öğrenme ve derin öğrenme yöntemleri uygulanarak osteoartrit hastalığını erken teşhisi yapılabilmektedir (Ozturk ve ark., 2017).

\section{Materyal ve Metot}

Termal kamera, nesneden yaklaşık $50 \mathrm{~cm}$ uzaklıkta bir odak mesafesine yerleştirilmiş olup kontrast ortam 1sısı ile dengeleme yapılmıştır. Termal kamera, 1sı ölçeğini ortamdaki en soğuk ve en sıcak noktalara göre otomatik olarak ayarlamıştır. $\mathrm{Bu}$ görüntüler farklı bireylerden alınmıştır. Bu bireylerin her iki dizi veya bir dizi yaralı ve bir dizi sağlıklı yahut da komple sağlıklıdır. Şekil 1'de çalışmanın akış diyagramı verilmiştir.

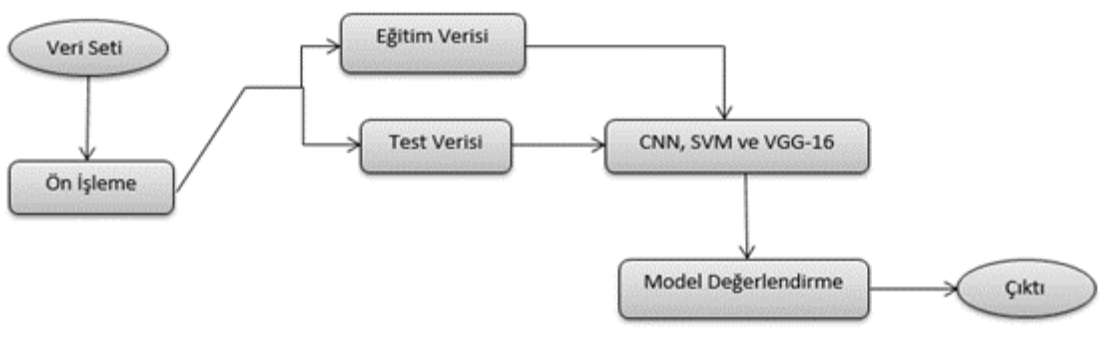

Şekil 1. Çalışma şeması

\subsection{Veri Kümesinin Hazırlanması}

Termografik görüntülerin sayısı toplam 998 görüntüden oluşmaktadır. Bu görüntülerin 284'ü hasta olup 714'ü de kontrol grubundan elde edilmiştir. Toplanan görüntüler üzerinde ölçüme işleme uygulanmıştır. Derin öğrenme ve makine öğrenme modelleri, modelin önceden görmediği görüntülerde hastalığ1 tespit etmek ve sınıflandırmak için görüntüler üzerinde değerlendirilmiş ve eğitilmiştir. Önerilen modellerde veri seti 'hasta' ve 'sağlam' olmak üzere yeniden ölçeklendirilmiştir. Şekil 2'de IR ile alınan hasta ve sağlıklı diz görüntüleridir.
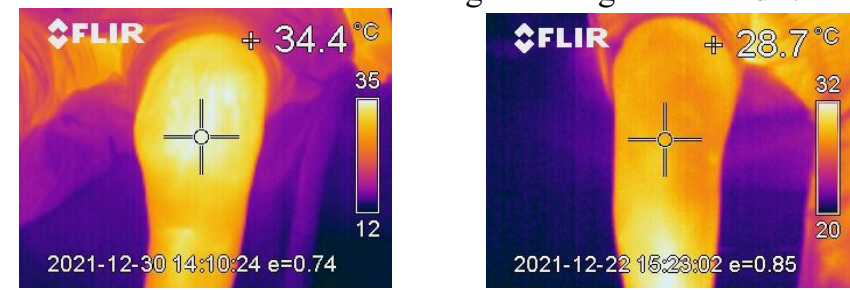

Şekil 2. IR ile hasta ve sağlam diz görüntüleri
Toplanan görüntüler üzerinde görüntü işleme yöntemleri uygulanmış olup ESA, evrişim katmanları, havuz katmanları ve tamamen bağlı katmanlar şeklinde olan üç temel sinir katmanından oluşmaktadır. ESA'nın girdisi 64, 64, 3 piksel görüntülerdir. 16, 3, 3 boyutunda bir evrişim katmanı vardır. Daha sonra, görüntünün yüksekliğini ve genişliğini $2 \times 2$ 'e düşüren bir maksimum havuz katmanı bulunmaktadır. Daha sonra düzleştirilmiş doğrusal birim katmanı, seyreltme katmanı son olarak da çıktı katmanı bulunmaktadır. Uygulanmış olan SVM metodu ise Sklearn'de SVM kullanılması kapsamında birkaç önemli değişkenler, doğrusal çekirdek, radyal temel işlev çekirdeği ve sigmoid çekirdeği uygulanmıştır. Uygulanmış olan

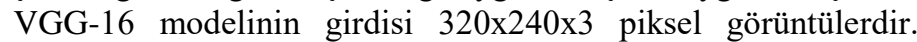
Ardından görüntünün yüksekliğini ve genişliğini düşüren bir havuz katmanı bulunmaktadır. Daha sonra düzleştirilmiş doğrusal birim katmanı vardır. En son olarak çıktı katmanı bulunmaktadır.

\subsection{Python Programlama Arayüzü}

Tkinter, Python için "standart" GUI araç takımıdır. Tkinter, ilk olarak 90'ların başında popüler hale gelen dil eşleştirmesi 
olan Tcl/ Tk'yi çevreleyen bir sarmalayıcı olup popüler bir grafik arabirimidir. Tkinter modülünü uygulamadan önce ESA metodunu kaydetmenin (model.save) amacı, hastalığı teşhis etmek için zamandan kazanmaktır. Şekil 3'te arayüz programının oluşturma akış şeması gösterilmiştir.

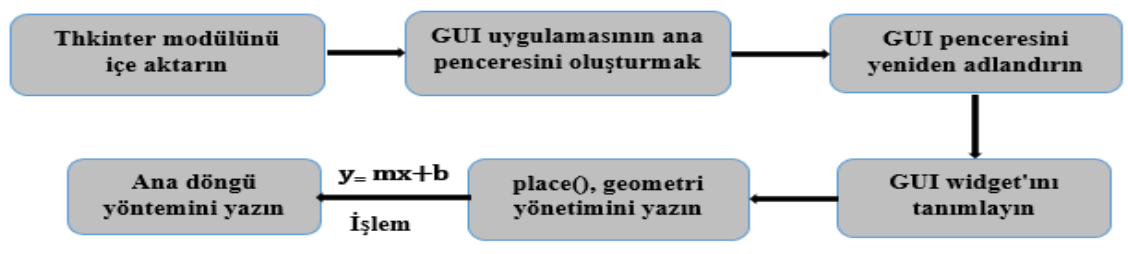

Şekil 3. Arayüz oluşturmak için akış şeması

Yukarıdaki akış şemasını bölümlenmesi ve her bir bileşenin işlevi aşağıda anlatılmaktadır.

- İlk aşamada, Tkinter modülü içe aktarılır.

- Sonraki adımda, pencere yöneticisi Tkinter'1 Tk()yöntemle başlatılır ve bir değişkene atanır. Bu yöntem, normal bir GUI'de olması gerektiği gibi üstte kapat, büyüt ve küçült düğmeleri olan boş bir pencere oluşturur.

- Daha sonra, Rename pencerenin başlığı isteye göre adlandırılır, root.title ('Osteoartrit Teşhis Arayüzü').

- Daha sonra, pencereye metin eklemek için kullanılan Label adlı bir widget çă̆rı kullanılır.

- Ardından, parçacığı gereken boyutta görüntülemek için Tkinter'ın place () adlı geometri yönetimi özelliği kullanılır.

- Ardından, Canvas, GUI'de şekiller çizmek için kullanılır ve çeşitli çizim yöntemlerini destekler, canvas = Canvas ().

- Ardından, görüntü programa yüklendiğinde, Teşhis butonuna tıklayarak program hastalığı teşhis etme tahmininde bulunur

$$
\text { model = load_model. }
$$

- Son adım olarak, pencereyi manuel olarak kapatana kadar görüntülemek için mainloop () adımı uygulanır. Arka uçta sonsuz bir döngü çalıştırılır.

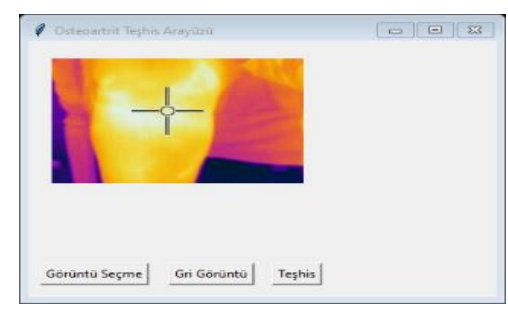

Şekil 4. Hasta görüntüsü

\section{Araştırma Sonuçları ve Tartışma}

$\mathrm{Bu}$ çalışma, IRT'nin OA'lı katılımcılarda ölçülebilir cilt sıcaklıkları modellerini saptamak için güvenilir bir tanı aracı olarak gösterilmiştir. Termal kamera kullanılarak elde edilen görüntülerde hastalığın teşhisi yapılamazken, ESA, DVM ve VGG-16 işleme yöntemlerini kullanılarak görüntülerde diz osteoartriti tespit edilebilmektedir. Daha sonra bu yöntemler arasında en yüksek doğruluk oranını ortaya koymuş olan ESA (\%90)'yı arayüz grafiği ile işleyerek hastalığın teşhisinde doktora yardımcı olabilecek bir yöntem geliştirilmiştir.
Katılımcıların dizlerinin normal ve OA'lı eklemlerindeki yüzey sıcaklığı ölçülmüştür. IRT, deneyler sırasında sabit bir odada yapılmış olup hastalar muayeneden önce bilgilendirilip onayları alınmıştır. Sıcaklık kontrollü bir ortamda IRT'nin birden fazla tekrarlanarak çalıştırıldığı ve bilgisayar destekli programlarla daha güvenilir bir sonuça ulaşıldığı birçok çalışmada ortaya konmuştur. IRT, cilt sıcaklığı dağılımları yoluyla diz osteoartritini saptamada güvenilirdir. Ayrıca diz cilt 1Sısı ile OA'ya bağlı ağrı şiddeti arasında korelasyon gözlenmiştir.

\section{Sonuç}

$\mathrm{Bu}$ çalışmada termografik görüntülerin derin öğrenme ve makine öğrenme yöntemleri ile sınıflandırılması yapılmıştır. Görüntü işleme yöntemleri uygulayarak ESA modelinden doğruluk \%90, VGG-16 modelinden \% 69.23 ve SVM modelinden \%77 doğruluk oranı elde edilmiştir. Söz konusu görüntü işleme yöntemleri arasında en yüksek ve en başarılı doğruluk oranı ESA modelinde ortaya çıkmıştır. Phyton programlama dili büyük performansından dolayı önerilen sistemin tasarımında ve programlanmasında, ESA modeli ile kullanılmıştır. Termal görüntüleme kullanılarak hastalığ etme sürecinde doktora yardımcı olabilecek bir sistem tasarlanmıştır. Toplanan görüntüler istatistik paket programına girilmiş olup tüm istatistiksel analizlerde $\mathrm{p}<0.05$ düzeyinde anlamlı olarak değerlendirilmiştir.

\section{Teșekkür}

Özel Ankara Cerrahi Tıp Merkezi, Özel Ankara Umut ve Ankara Gazi Üniversitesi hastanelerinin Ortopedi bölümünde gerekli görüntüler sağlandığı için şükranlarımı sunarım.

\section{Kaynakça}

Lecun, Y., Bottou, L., Bengio , Y., \& Haffner, P. (1998). Gradient-based learning applied to document recognition. in Proceedings of the IEEE, vol. 86, no. 11, 2278-2324.

Anonymous. (2021, Mart 10). instrumentsgroup. 05 16, 2021 tarihinde instrumentsgroup Web Sitesi: http://www.instrumentsgroup.com.za/index_files/Flir/Learn/ Elec.Mech Diagnostics.pdf adresinden alınd1.

Bijlsma, J. W., Berenbaum, F., \& Lafeber, F. P. (2011). Osteoarthritis: an update with relevance for clinical practice. The Lancet, 377(9783), 2115-2126. 
Erdem, E., \& Aydın, T. (2021). Detection of Pneumonia with a Novel CNN-based Approach. Sakarya University Journal of Computer and Information Sciences, 4(1), 26-34.

Felson, D. T., Zhang, Y., Hannan, M. .., Naimark, ,. a., Weissman, B., Aliabadi, P., \& Levy, D. (1995). The incidence and natural history of knee osteoarthritis in the elderly. Arthritis \& Rheumatism, 1500-1505.

Krizhevsky , A., Sutskever, I., \& Hinton, G. (2012). Derin evrişimli sinir ağları ile Imagenet sınıflandırması. Sinirsel bilgi işleme sistemlerindeki gelişmeler , 25, 1097-1105.
Lawrence, R. C., Felson, D. T., Helmick, C. G., Arnold, L. M., Choi, H., \& Deyo, R. A. (2008). Estimates of the prevalence of arthritis and other rheumatic conditions in the United States. Part II. Arthritis \& Rheum 58(1), 26-35.

Öztürk, Ş., Özkaya, U., Akdemir, B., \& Seyfi, L. (2017). Soft Tissue Sacromas Segmentation using Optimized Otsu Thresholding Algorithms. Int J Eng Technol Manag Appl Sci, 5, 49-54. 